damage. ${ }^{3,4}$ Our patient was well anticoagulated with warfarin and his clotting markers were normal; however, he did have two hypercoagulability factors-namely, diabetes $^{7}$ and a paraproteinaemia. ${ }^{8}$ We conclude that, in a patient such as this with unexplained fever and abdominal symptoms, a history of upper respiratory tract infection should be sought and blood cultures should be taken to detect this fastidious anaerobic organism.

\title{
REFERENCES
}

1 Lemierre A. On certain septicaemias due to anaerobic organisms. Lancet 1936;i:701-3

2 Soo R, Gosbell I, Gallo J, Pokorny CS. Septic portal vein thrombosis due to Fusobacterium necrophorum. Aust NZ J Med 1999;29:569-70

3 Bultink IE, Dorigo-Zetsma J, Koopman MG, Kuijper EJ. Fusobacterium nucleatum septicemia and portal vein thrombosis. Clin Infect Dis 1999;28:1325-6

4 Etienne M, Gueit I, Abboud P, et al. Fusobacterium nucleatum hepatic abscess with pylephlebitis associated with idiopathic CD4(+) T lymphocytopenia. Clin Infect Dis 2001;32:326-8

5 Verna EC, Larghi A, Faddoul SG, Stein JA, Worman HJ. Portal vein thrombosis associated with Fusobacterium nucleatum septicemia in a patient with ulcerative colitis. J Clin Gastroenterol 2004;38:611-12

6 El Braks R, Harnois F, Boutros N, et al. Mesenteric adenitis and portal vein thrombosis due to Fusobacterium nucleatum. Eur J Gastroenterol Hepatol 2004;16:1063-6

7 Sakkinen PA, Wahl P, Cushman M, Lewis MR, Tracy RP. Clustering of procoagulation, inflammation, and fibrinolysis variables with metabolic factors in insulin resistance syndrome. Am J Epidemiol 2000;152:897907

8 Eby C, Blinder M. Hemostatic complications associated with paraproteinemias. Curr Hematol Rep 2003;2:388-94

\section{Perindopril and pulmonary eosinophilic syndrome}

\section{A P Rochford BSc MRCP ${ }^{1}$ P R Smith MSc MRCP2 S J Khan MRCP $^{1} \quad$ A J G Pearson MB FRCP ${ }^{1}$}

J R Soc Med 2005;98:163-165

Angiotensin converting enzyme (ACE) inhibitors are responsible for several respiratory effects including cough and angioneurotic oedema but an association with pulmonary eosinophilic syndrome is uncommon.

${ }^{1}$ Barnet \& Chase Farm Hospitals NHS Trust, Wellhouse Lane, Barnet, Herts EN5 3DJ; ${ }^{2}$ Department of Infectious Diseases and Microbiology, Institute of Child Health, 30 Guilford Street, London WC1N 1EH, UK

Correspondence to: Dr A P Rochford, Department of Gastroenterology, Barnet \& Chase Farm Hospitals NHS Trust, Thames House, Wellhouse Lane, Barnet EN5 3DJ, UK

E-mail: Andrew.Rochford@ukgateway.net

\section{CASE HISTORY}

A Caucasian woman aged 68 was seen after two weeks of malaise, nausea and sinusitis, for which she had been prescribed clarithromycin. Seven weeks earlier she had been started on perindopril for hypertension, at which time a full blood count was normal. She was also taking co-amilofruse and was using inhaled medications for asthma - fluticasone, begun eighteen months earlier to replace the oral prednisolone she had taken for 15 years, and salbutamol. There was no travel history of note and she kept no household pets. On examination she was apyrexial. No abnormal physical signs were detected - in particular no rash or subcutaneous nodules. Blood pressure was 109/ $80 \mathrm{mmHg}$ and oxygen saturation $97 \%$ on air. Haemoglobin was $10.1 \mathrm{~g} / \mathrm{dL}$, MCV $93 \mathrm{fL}$, neutrophils $9.9 \times 10^{9} / \mathrm{L}$ and the eosinophil count was $13.4 \times 10^{9} / \mathrm{L}$ (52\%). Platelet count and clotting studies were normal; sodium was $128 \mathrm{mmol} / \mathrm{L}$, potassium $4.8 \mathrm{mmol} / \mathrm{L}$, urea $4.5 \mathrm{mmol} / \mathrm{L}$, creatinine $58 \mu \mathrm{mol} / \mathrm{L}$, albumin $31 \mathrm{~g} / \mathrm{L}$, corrected calcium $2.38 \mathrm{mmol} / \mathrm{L}$, C-reactive protein $86 \mathrm{mg} / \mathrm{L}$. There was no active urinary sediment. On sinus radiography the ethmoid and maxillary sinuses were opaque. A chest radiograph showed hyperinflated lungs and a small area of pleural scarring at the left costophrenic angle.

On admission to hospital, perindopril, clarithromycin and the diuretic were withdrawn, and she was continued on a fluticasone inhaler. A low-grade pyrexia developed and on day 6 the eosinophil count had risen to $18.3 \times 10^{9} / \mathrm{L}$ (61\%). CT revealed pulmonary infiltrates with mediastinal lymphadenopathy but no proximal bronchiectasis (Figure 1). Further investigations showed aspergillus precipitins weakly positive at titre $1: 2, \operatorname{IgE} 576 \mathrm{kU} / \mathrm{L}$ (normal $0-81$ ), stool examination negative for ova, cysts and parasites, and

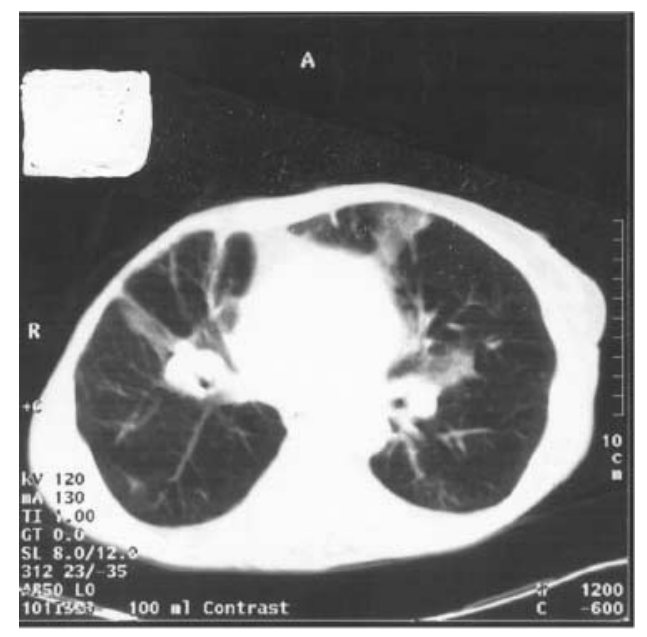

Figure 1 CT of thorax showing prominent peripheral infiltrates in the anterior segments of upper lobes and precarinal lymphadenopathy, an opacity at the right apex and bilateral pleural effusions 
(a)

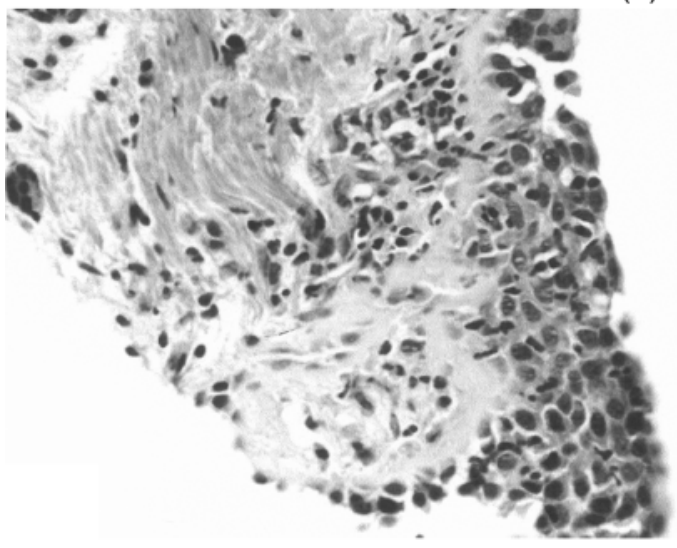

(b)

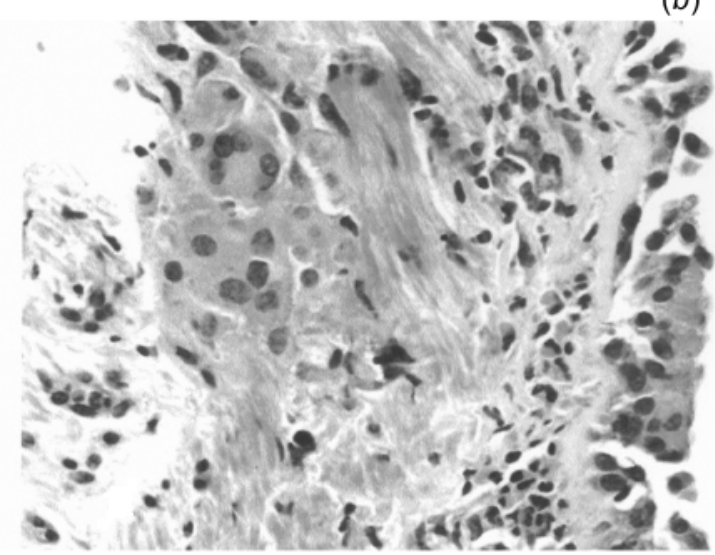

Figure 2 Transbronchial lung biopsy (haematoxylin and eosin $\times 125)$ showing (a) eosinophilic cellular infiltrate with necrosis and occasional multinucleated giant cells (b) but no evidence of vasculitis

echocardiogram normal. Serum angiotensin converting enzyme, extractable nuclear antibodies, antinuclear antibodies (ANA) and antineutrophil cytoplasmic antibodies (ANCA) were negative. On a short Synacthen (tetracosactide) test a baseline cortisol of $93 \mu \mathrm{g} / \mathrm{dL}$ rose to $119 \mu \mathrm{g} / \mathrm{dL}$, indicating adrenal insufficiency. A bone marrow aspirate and trephine biopsy showed normal bone marrow precursors with no evidence of underlying malignancy.

After a bronchoscopy she became nauseated and hypotensive, and the eosinophil count rose further to $25.5 \times 10^{9} / \mathrm{L}(72 \%)$. She was treated with a single dose of $100 \mathrm{mg}$ intravenous hydrocortisone and within forty-eight hours the eosinophil count had fallen to $0.1 \times 10^{9} / \mathrm{L}$ $(<1 \%)$. She was then started on oral hydrocortisone replacement therapy $(20,10,10 \mathrm{mg}$ per day).

A transbronchial biopsy showed a pronounced eosinophilic infiltrate but no evidence of vasculitis (Figure 2). A long Synacthen test suggested preserved adrenal function, but an undetectable baseline morning cortisol was in keeping with insufficiency at the level of the hypothalamopituitary axis. This was presumed secondary to previous long-term steroid use and she continues on oral hydrocortisone replacement therapy at doses of 10,5 and $5 \mathrm{mg}$ per day. Repeat CT of the thorax six months later was normal and autoantibody screening, adrenal antibodies, ANA and ANCA were persistently negative. At twenty-four months her asthmatic symptoms remained well controlled on fluticasone and the eosinophil count was normal.

\section{COMMENT}

Peripheral eosinophilia can be caused by allergic disorders, parasitic infections, lymphoproliferative disorders, solid tumours, gastrointestinal diseases, skin conditions, collagen vascular diseases and systemic vasculitides. ${ }^{1}$ Drug-induced exclusion of other diagnoses. ACE inhibitors are associated with cough, and hypersensitivity lung disease is increasingly recognized in connection with these agents. Eosinophilic syndromes have been attributed to captopril, ${ }^{2}$ enalapril ${ }^{3}$ and fosinopril. ${ }^{3}$ In these instances the eosinophilia was not as great as that reported here. The temporal relation of perindopril treatment and clinical features of hypersensitivity point to the causal involvement of this ACE inhibitor in our patient with eosinophilic pneumonia-an adverse reaction that has not previously been reported with this agent. Rechallenge with perindopril was considered too hazardous to be justifiable.

Other medications implicated in drug-induced pulmonary eosinophilic syndromes include antibiotics and nonsteroidal anti-inflammatory agents. ${ }^{4}$ Terzano et al. ${ }^{5}$ report a patient with asthma who developed fever and pulmonary infiltrates with eosinophilia after taking clarithromycin, on two separate occasions, responding to withdrawal of the antibiotic and institution of corticosteroid treatment. Our patient received clarithromycin before presentation but has since been unintentionally rechallenged without recurrence of pulmonary infiltrates or eosinophilia.

It is possible, in view of her history of asthma, that she had an underlying vasculitic process that was partly controlled by the inhaled fluticasone; systemic absorption of inhaled steroids is recognized. ${ }^{6}$ We feel that the absorbed pulmonary steroid combined with the current oral steroid dose would be insufficient adequately to control a vasculitis. Her ANCA was also negative and there were no other clinical features to support a diagnosis of vasculitis. The diagnosis of Churg-Strauss syndrome should be suspected in any patient presenting with eosinophilia, asthma, pulmonary infiltrates and evidence of vasculitis. The asthma is usually of late onset and may become more severe with time. ${ }^{7}$ Extrapulmonary features can be helpful in distinguishing Churg-Strauss from chronic eosinophilic 
pneumonia and allergic bronchopulmonary aspergillosis: in particular Churg-Strauss manifests, in up to $75 \%$ of patients, with mononeuritis multiplex. ${ }^{7}$ At twenty-four months our patient remained free from neurological symptoms, and had no evidence of cardiac, skin, joint or renal involvement. Hypereosinophilic syndrome may represent a preleukaemic state, or may herald the onset of Hodgkin's disease or T-cell lymphoblastic lymphoma. ${ }^{8}$ An underlying lymphoproliferative or myeloproliferative disorder is unlikely in the present case in view of the normal bone marrow, rapid response to hydrocortisone and lack of recurrence of the peripheral eosinophilia. Mild eosinophilia associated with adrenocortical insufficiency is well recognized in critically ill patients. However, the pulmonary infiltrates, mediastinal lymphadenopathy and marked eosinophilia seen in our patient cannot be explained by hypocorticism. Furthermore, the strong IgE response suggests a hypersensitivity phenomenon such as a drug reaction.

Acknowledgments We thank Dr Jeremy Berger for his assistance with diagnostic radiology, Dr Andrew Gallimore for providing histopathology images and Dr Adrian Barnes for his helpful comments.

\section{REFERENCES}

1 Lombardi C, Passalacqua G. Eosinophilia and diseases: clinical revision of 1862 cases. Arch Intern Med 2003;163:1371-3

2 Schatz PL, Mesologites D, Hyun J, Smith GK, Lahiri B. Captoprilinduced hypersensitivity lung disease. An immune-complex-mediated phenomenon. Chest 1989;95:685-7

3 Benzaquen-Forner $\mathrm{H}$, Dournovo $\mathrm{P}$, Tandjaori-Lambiotte $\mathrm{H}$, et al. Hypoxic eosinophilic pneumonia in two patients treated with ACE inhibitors. Rev Mal Respir 1998;15:804-10

4 Camus PH, Foucher P, Bonniaud PH, Ask K. Drug-induced infiltrative lung disease. Eur Respir J 2001;18(suppl. 32):93-1005

5 Terzano C, Petroianni A. Clarithromycin and pulmonary infiltration with eosinophilia. BMJ 2003;326:1377-8

6 White A, Woodmansee DP. Adrenal insufficiency from inhaled corticosteroids. Ann Intern Med 2004; 140:E-497

7 Conron M, Beynon HLC. Churg-Strauss syndrome. Thorax 2000;55:870-7

8 Weller PF. The idiopathic hypereosinophilic syndrome. Blood 1994;83:2759-79

\section{Renal bone disease}

\author{
Jeffrey $\mathrm{H}$ M Lee MRCP Malcolm Stodell FRCP \\ J C Fowler FRCR
}

J R Soc Med 2005;98:165-166

In rare instances of renal failure a clue to the underlying disease can be had from plain skeletal radiographs.

\section{CASE HISTORY}

A man of 65 was referred after five months of lethargy and poor appetite, with loss of $12 \mathrm{~kg}$ in weight. He had a history of hypertension and glaucoma and for several years had been taking quinapril and atenolol and using latanoprost eye drops. On clinical examination the only noteworthy finding was pallor. Haemoglobin was $8.7 \mathrm{~g} / \mathrm{dL}$ and MCV $72.8 \mathrm{fL}$, erythrocyte sedimentation rate $93 \mathrm{~mm} / \mathrm{h}$, creatinine $205 \mu \mathrm{mol} / \mathrm{L}$ (having been $117 \mu \mathrm{mol} / \mathrm{L} 2$ years previously).

On the chest X-ray the mediastinal contour was normal and the lungs were clear but unusual symmetrical sclerotic changes were noted in the humeral metaphyses (Figure 1). Bone scintigraphy revealed symmetrically increased uptake predominantly in the long bones, affecting the metaphyses and adjacent diaphyses, with sparing of the epiphyses especially within the distal femora and proximal humeri (Figure 2). On plain films a coarsening of bone texture correlated with the scintigraphic uptake. This strongly suggested a diagnosis of Erdheim-Chester disease, and CT of the abdomen reinforced this impression, revealing stranding of retroperitoneal soft tissues, especially in the perinephric fat, causing mild hydronephrosis (Figure 3). Because this combination of findings was so typical we did not seek biopsy confirmation. He was started on prednisolone and nine months later, taking $5 \mathrm{mg}$ daily, he was feeling well, with serum creatinine $167 \mu \mathrm{mol} / \mathrm{L}$ and creatinine clearance $29 \mathrm{~mL} / \mathrm{min}$.

\section{COMMENT}

Erdheim-Chester disease is a histiocytosis characterized by diffuse infiltration of the affected organs by lipid-laden histiocytes and Touton-type giant cells, immunohistochemically different from Langerhans-cell histiocytosis. ${ }^{1}$ Radiologically, the most specific finding is bilateral and symmetrical cortical osteosclerosis affecting mainly the metaphyseal and diaphyseal regions of the long bones with sparing of the epiphyses. ${ }^{2}$

Departments of ${ }^{1}$ Medicine and ${ }^{2}$ Radiology, Luton and Dunstable NHS Trust, Lewsey Road, Luton LU4 ODZ, UK

Correspondence to: Dr Malcolm Stodell

E-mail: malcolm.stodell@Idh-tr.anglox.nhs.uk 